\title{
Efficacy of fixed dose of triple combination of perindopril-indapamide-amlodipine in obese patients with moderate-to-severe arterial hypertension: an open-label 6-month study
}

\author{
Sergiy M. Koval ${ }^{1 \odot}$, Iryna O. Snihurska ${ }^{2 \oplus}$, Tetyana G. Starchenko ${ }^{2 \oplus}$, Marina Yu. Penkova ${ }^{2 ®}$, \\ Olga V. Mysnychenko ${ }^{\circledR}$, Kostyantin O. Yushko ${ }^{2}{ }^{\circledR}$, Olga M. Lytvynova ${ }^{\circledR}$, Olena Vysotska ${ }^{4}{ }^{\circledR}$, \\ Alexander E. Berezin ${ }^{5, * 0}$
}

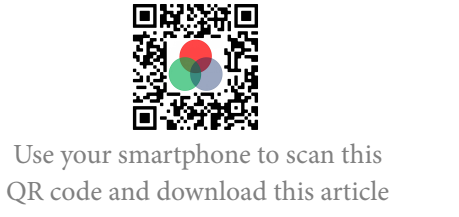

${ }^{1}$ Department of Arterial Hypertension and Prevention of Its Complications, Government Institution " L.T. Malaya Therapy National Institute of the National Academy of Medical Science of Ukraine", 2A Lyubovi Maloi av., Kharkiv, UA-61039, Ukraine

${ }^{2}$ Department of Hypertension and Prevention of Its Complications, Government Institution " L.T. Malaya Therapy National Institute of the National Academy of Medical Science of Ukraine", 2A Lyubovi Maloi av. Kharkiv, UA-61039, Ukraine

${ }^{3}$ Department of Laboratory Diagnostics, National University of Pharmacy Puskinska str.,53, Kharkiv, UA-61002, Ukraine

\section{Correspondence}

Alexander E. Berezin, Internal Medicine Department, State Medical University of Zaporozhye, 26, Mayakovsky av., Zaporozhye, UA-69035, Ukraine

Email: dr_berezin@mail.ru

History

- Received: Aug 24, 2019

- Accepted: Nov 10, 2019

- Published: Nov 30, 2019

DOI : 10.15419/bmrat.v6i11.578

\section{Check for updates}

\section{Copyright}

(๑) Biomedpress. This is an openaccess article distributed under the terms of the Creative Commons Attribution 4.0 International license.

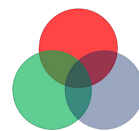

BioMedPress

The Open Access Publisher

ABSTRACT

Background: Arterial hypertension (AH) remains the most common cardiovascular (CV) risk factor worldwide. Methods: Seventy five moderate-to-severe hypertensive patients with abdominal obesity aged from 48 to 66 years (45/30 men and women respectively) were selected from the entire cohort ( $n=375$ ) according to the inclusion and exclusion criteria. The patients were divided into two subgroups depending on the arm of antihypertensive therapy lines. The first subgroup of patients $(n=36)$ received a non-fixed combination of oral antihypertensive agents: perindopril (4-8 mg daily), indapamide (1.25-2.5 mg daily) and amlodopine (5-10 mg daily). The second subgroup of patients $(n=39)$ received fixed-dosed combination of these antihypertensive agents aforementioned in the ranged doses $(4 \mathrm{mg} / 1.25 \mathrm{mg} / 5 \mathrm{mg} ; 4 \mathrm{mg} / 1.25 \mathrm{mg} / 10 \mathrm{mg} ; 8 \mathrm{mg} / 2.5 \mathrm{mg} / 5 \mathrm{mg} ; 8$ $\mathrm{mg} / 2.5 \mathrm{mg} / 10 \mathrm{mg}$ ) in the same manner. The examinations of the clinical status, office, and ambulatory blood pressure values were carried out at baseline in 3 and 6 months after study entry. Results: The frequencies of BP target levels after treatment were higher in the fixed-dose combination group than in the non-fixed combination (at 3 months: $80 \%$ versus $58 \%, p<0.05$ and at 6 months: $85 \%$ versus $53 \%, p<0.05)$. The adherence to triple fixed-dose combination was also higher in comparison with one to non-fixed combination (at 3 months: $82 \%$ versus $64 \%, \mathrm{p}<0.05$ and at 6 months: $87 \%$ versus $61 \%, \mathrm{p}<0.05)$. It has been established that low-dose of perindopril/indapamide/amlodopine (4mg/1.25/10 mg and $8 \mathrm{mg} / 2.5 / 5 \mathrm{mg}$ ) were used frequently in fixed-dose combination cohort of patients than in non-fixed combination ( $15 \%$ versus $0 \%, P<0.05$, and $33 \%$ versus $19 \%$, $p<0.05$, respectively). At the same time, maximum doses of these agents $(8 \mathrm{mg} / 2.5 \mathrm{mg} / 10 \mathrm{mg})$ were required for achieving target BP levels in a significantly lower proportion of patients receiving fixed-dose combination as compared to patients receiving non-fixed combination ( $52 \%$ versus $81 \%, \mathrm{p}<0.05$ ). Additionally, the triple fixed-dose combination has proved to be better in restoring ambulatory blood pressure monitoring profile than non-fixed combination. Conclusion: Achievement of target blood pressure levels in patients with uncontrolled arterial hypertension and abdominal obesity was possible at lower doses of perindopril, indapamide, and amlodipine when used as a fixed-dose combination rather than non-fixed (free) combination.

Key words: abdominal obesity, antihypertensive therapy, arterial hypertension, fixed-dose combination of antihypertensive agents, non-fixed combination of antihypertensive agents

\section{INTRODUCTION}

Arterial hypertension (AH) is the most common cardiovascular $(\mathrm{CV})$ risk factor worldwide ${ }^{1,2}$. Prevalence of $\mathrm{AH}$ in European countries fluctuates from $20 \%$ to $50 \%$ of the adult population ${ }^{3,4}$. $\mathrm{AH}$ is frequently associated with various metabolic diseases including abdominal obesity $(\mathrm{AO})^{5,6}$. In fact, at least $60 \%$ of $\mathrm{AO}$ patients were reported having mildto-moderate $\mathrm{AH}^{7}$ and $15-20 \%$ of them had severeto-refractory $\mathrm{AH}^{8}$. Moreover, endothelial dysfunc- tion, dyslipidaemia, insulin resistance (IR), increased serum uric acid (SUA) - hypeuricemia (HUE), microvascular inflammation, which are accompanied to both $\mathrm{AH}$ and $\mathrm{AO}$, can accelerate atherosclerosis, mediate pro-coagulation state and sufficiently elevate a risk of $\mathrm{CV}$ complications ${ }^{9-11}$. In this context, tight control for systolic and diastolic blood pressures (BP) at target levels (generally $<140 / 90 \mathrm{~mm} \mathrm{Hg}$ ) is considered a useful tool for improving survival and preventing life-threatening events ${ }^{12,13}$. Unfortunately,

Cite this article : Koval S M, Snihurska I O, Starchenko T G, Penkova M Y, Mysnychenko O V, Yushko K O, Lytvynova O M, Vysotska O, Berezin A E. Efficacy of fixed dose of triple combination of perindoprilindapamide-amlodipine in obese patients with moderate-to-severe arterial hypertension: an open-label 6-month study. Biomed. Res. Ther.; 6(11):3501-3512. 
${ }^{4}$ Head of Department of radioelectronic and biomedical computeraided means and technologies, National Aerospace University "Kharkiv Aviation Institute", Chkalov street, 17, Kharkiv, UA-61070, Ukraine

${ }^{5}$ Internal Medicine Department, State Medical University of Zaporozhye, 26, Mayakovsky av., Zaporozhye, UA-69035, Ukraine double and triple combined anti-hypertensive therapy did not correspond to achieve target level of BP in many cases in patients with $\mathrm{AO}^{14}$. Previous studies have shown that more than half of patients needed double therapies to achieve full control in BP, while $20-30 \%$ of patients required triple combination and ever more ${ }^{15-17}$. It has been postulated that poor adherence to antihypertensive treatment, respectively high frequency of adverse effects and low tolerability could be the main causes to withdraw from the therapy ${ }^{18}$. Early prescription of triple fixed-dose combination could improve patient response to the treatment and consequently decrease CV risk. Substantiated triple fixed-dose combinations of angiotensinconverting enzyme (ACE) inhibitor perindopril (P), thiazide-like diuretic (TLD) indapamide (Ind), and long-acting dihydropyridine calcium channel blocker (CCB) amlodipine (Aml) is considered most promising to achieve high efficacy and superiority in safety when compared with the same non-fix dose combination ${ }^{19}$. The study aimed to investigate the efficacy of triple fixed-dose versus the non-fixed combination of $\mathrm{P}+\mathrm{Ind}+\mathrm{Aml}$ in obese patients with moderate-tosevere $\mathrm{AH}$.

\section{METHODS}

Seventy-five moderate-to-severe hypertensive patients with $\mathrm{AO}$ aged from 48 to 66 years (45 men and 30 women) were selected from the entire cohort $(\mathrm{n}=375)$ according to the inclusion and exclusion criteria (Figure 1). Inclusion criteria were patients with uncontrolled hypertension (systolic and/or diastolic BP levels > 140/90 mm Hg despite previous anti-hypertensive treatment with double drugs combination) at the study entry, age $>18$ years and with written informed consent to participation in the study. Non-inclusion criteria includes patients with an acute coronary syndrome, acute myocardial infarction, heart failure, type 2 diabetes mellitus, angina pectoris, severe chronic renal failure, acute and chronic inflammatory diseases, severe liver insufficiency, chronic obstructive pulmonary disease, bronchial asthma, pregnancy, malignancy, and disability to know the reason of informed consent.

\section{Study Design}

This is an open-label, randomized, parallel-group and controlled study.

After the initial examination, the patients were divided into two subgroups depending on the arm of anti-hypertensive therapy lines. The first subgroup of patients $(n=36)$ received a non-fixed combination of -anti-hypertensive agents, which include ACE inhibitor P (4-8 mg daily orally), TLD Ind (1.25-2.5 mg daily orally) and dihidroperidine CCB Aml (5$10 \mathrm{mg}$ daily orally) non-fasting in the morning. The second subgroup of patients $(n=39)$ received fixeddosed combination of these anti-hypertensive agents mentioned above in the ranged doses $(4 \mathrm{mg} / 1.25 \mathrm{mg} / 5$ $\mathrm{mg} ; 4 \mathrm{mg} / 1.25 \mathrm{mg} / 10 \mathrm{mg} ; 8 \mathrm{mg} / 2.5 \mathrm{mg} / 5 \mathrm{mg} ; 8$ $\mathrm{mg} / 2.5 \mathrm{mg} / 10 \mathrm{mg}$ ) in the same manner. The examinations of the clinical status, office BP value was carried out at baseline, and in 3 and 6 months after the study entry, and ambulatory BP value was carried out at baseline and at 6 months after treatment. For target, BP levels systolic and diastolic BP $<140 / 90 \mathrm{~mm} \mathrm{Hg}$ were taken. All patients received recommendations about life-style modifications, and they were treated with atorvastatin $20 \mathrm{mg}$ daily as a concomitant medication due to high-to very high CV risk.

\section{Ethical declaration}

The study was approved by the local Ethical Committee (Government Institution "L.T. Malaya Therapy National Institute of the National Academy of Medical Science of Ukraine," date of approval was 18.01.2018). All patients have given their voluntary informed consent to participate in the study.

\section{Determination of $\mathrm{AH}$}

$\mathrm{AH}$ was diagnosed if systolic blood pressure (SBP) was $>140 \mathrm{~mm} \mathrm{Hg}$, and/or diastolic blood pressure (DBP) $>90 \mathrm{~mm} \mathrm{Hg}$, according to European guideline on diagnostics and treatment of arterial hypertension $(2018)^{5}$, or a self-reported history of hypertension, and/or the use of anti-hypertensive medications.

\section{Determination of risk factors and comor- bidities}

\section{Determination of dyslipidemia}

Dyslipidemia was diagnosed if total cholesterol (TC) level was above $5.2 \mathrm{mmol} / \mathrm{L}$, and/or low density lipoproteid cholesterol (LDL) level was above 3.0 $\mathrm{mmol} / \mathrm{L}$, and/or triglyceride (G) level was above 1.7 mmol/L according to with European Cardiology Society dyslipidemia guideline $(2016)^{20}$, or use of lipidlowering medication.

\section{Determination of $A O$}

AO was defined as a body mass index (BMI) $\geq 30$ $\mathrm{kg} / \mathrm{m}^{2}$, waist circumference $\geq 90 \mathrm{~cm}$ in men or $\geq 80$ $\mathrm{cm}$ in women ${ }^{21}$. 


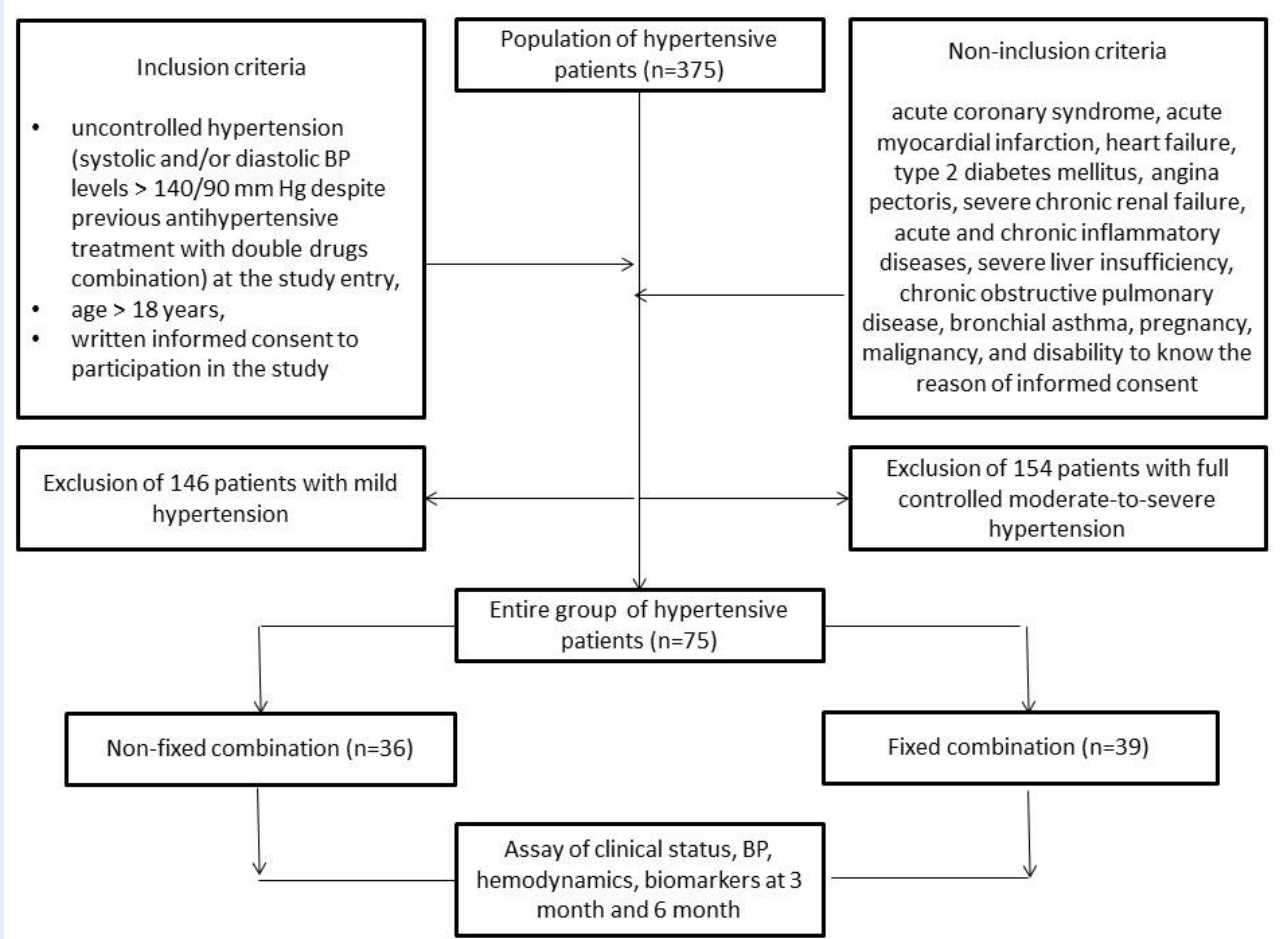

Figure 1: Flow chart with including/excluding criteria of the study.

\section{Determination of metabolic syndrome(MetS)}

MetS was diagnosed based on the National Cholesterol Education Program Adult Treatment Panel III criteria $^{22}$. Patients were enrolled in the MetS cohort when at least three of the following components were defined: waist circumference $\geq 90 \mathrm{~cm}$ in men or $\geq 80 \mathrm{~cm}$ in women; high density lipoprotein (HDL) cholesterol $<1.03 \mathrm{mmol} / \mathrm{L}$ in men or $<1.3 \mathrm{mmol} / \mathrm{L}$ in women; triglyceride levels $\geq 1.7 \mathrm{mmol} / \mathrm{L}$; blood pressure $\geq 130 / 85 \mathrm{mmHg}$ or current exposure of antihypertensive drugs; fasting plasma glucose $\geq 5.6$ $\mathrm{mmol} / \mathrm{L}$.

\section{Determination of HUE}

HUE was diagnosed when blood serum levels of uric acid were found to be higher than $360 \mu \mathrm{mol} / \mathrm{L}$.

\section{Determination of family history of coronary artery disease (CAD)}

A family history of CAD was defined if a first degree relative of any age was diagnosed with $\mathrm{CAD}$, as mentioned in the self-report questionnaire.

\section{Smoking status}

Current smoking was defined as consumption of one cigarette daily for three months ${ }^{23}$.

\section{Anthropometric measurements}

Anthropometric measurements (weight, height, body mass, body mass index [BMI], waist circumference, and waist-to-hip ratio) were made using standard procedures ${ }^{24}$. Height and weight were measured by professional health staff, with the participants standing without shoes and heavy outer garments with a wall-mounted stadiometer (OMRON, Japan). BMI was calculated as weight $(\mathrm{kg})$ divided by height squared $\left(\mathrm{m}^{2}\right)$. Waist circumference was measured at the level midway between the lower rib margin and the iliac crest, with participants in a standing position without heavy outer garments, with emptied pockets and breathing out gently. Hip circumference was recorded as the maximum circumference over the buttocks.

\section{Adherence to the treatment}

Adherence to the treatment was measured as a percentage of the patients, who were not dropped out 
from the treatment arm due to several reasons including low tolerability, lowed compliance or lost for follow-up.

\section{BP measure}

Office BP was measured with the conventional method using a sphygmomanometer (Microlife BP AG 1-10, Hungary).

\section{ECG recording}

Standard 12-lead electrocardiography was performed at rest according to the conventional method with a three-channel FX-326U ECG recorder (Fukuda, Japan).

\section{Ambulatory blood pressure monitoring (ABMP)}

ABPM was performed according to contemporary protocol $^{5}$ with AVRM-02/0 machine (Meditech, Hungary). Traditional parameters, such as SBP(24), average daily systolic $\mathrm{BP} ; \operatorname{DBP}(24)$, average daily diastolic BP; SBP(D), average daytime systolic BP; $\mathrm{DBP}(\mathrm{D})$, average daytime diastolic BP; $\mathrm{SBP}(\mathrm{N})$, average night-time systolic $\mathrm{BP} ; \mathrm{DBP}(\mathrm{N})$, average nighttime diastolic BP; $\operatorname{TISBP}(24)$, time-index 24-hour SBP TIDBP(24), time-index 24-hour DBP; DNSBPR, degree of night-time SBP reduction; DNDBPR, degree of night-time DBP reduction; SBPV(24), average daily SBP variability; DBPV(24) and average daily DBP variability, were calculated and interpreted.

\section{Echocardiography}

Echocardiography was conducted in M- and B-modes with a $2.5 \mathrm{MHz}$ phased probe using a medical diagnostic ultrasound complex SSD 280 LS (Aloka, Japan). The left ventricular myocardial mass (LVMM) and the LVMM index (LVMMI) were calculated by the formula of the American Society of Echocardiography. Left ventricular hypertrophy (LVH) was diagnosed when LVMMI increased to more than $50 \mathrm{~g} / \mathrm{m}^{2}$ in men and $47 \mathrm{~g} / \mathrm{m}^{2}$ for women ${ }^{5}$.

\section{B-mode vascular ultrasound}

B-mode common carotid artery (CCA) ultrasound examination was performed with a $7.5 \mathrm{MHz}$ linear array probe using colour flow mapping by ultrasound scanner (LOGIQ-5, Japan). Thickness of intima-media segment (IMT) was measured according to conventional method ${ }^{25}$ Carotid IM values $\leq$ $0.9 \mathrm{~mm}$ were considered to be normal, IM was registered when its value was more than $0.9 \mathrm{~mm}$, atheromatous plaques were registered when IMT value was
$>1.5 \mathrm{~mm}$, or when carotid artery was locally thickened by $0.5 \mathrm{~mm}$, or when IMT segment was up to $50 \%$ thicker than surrounding segments ${ }^{5}$.

\section{Calculation of glomerular filtration rate (GFR)}

GFR was calculated using CKD-EPI formula ${ }^{26}$.

\section{Blood sampling}

Blood samples were drawn immediately before study entry and at 6 months of investigation. Blood samples were centrifuged, serum was isolated within $30 \mathrm{~min}$ of sample acquisition and then freezed at $-70^{\circ} \mathrm{C}$ and stored in plastic tubes until being shipped to the laboratory of immune-chemical and molecular-genetic researches of Government Institution "L.T. Malaya Therapy National Institute of the National Academy of Medical Science of Ukraine".

\section{Biomarker assay}

The levels of plasma glucose, serum urea, creatinine, and uric acid were determined by enzymatic method using Humareazer 2000 analyzer (HUMAN GmbH, Germany).

Total cholesterol (TC), low density lipoprotein (LDL) cholesterol, high density lipoprotein (HDL) cholesterol, and triglyceride levels (TG) were measured by direct method on Humareazer 2106 analyser (HUMAN GmbH, Germany).

Hemoglobin Alc (HbAlc) were determined by highpressure liquid chromatography method.

Fasting insulin level was measured by doubleantibody sandwich immunoassay using commercial kits produced by DRG (Germany).

IR was assessed by the homeostasis model assessment for insulin resistance (HOMA-IR) ${ }^{27}$ using the following formula:

HOMA-IR $(\mathrm{mmol} / \mathrm{L} \times \mu \mathrm{U} / \mathrm{mL})=$ fasting glucose $(\mathrm{mmol} / \mathrm{L}) \times$ fasting insulin $(\mu \mathrm{U} / \mathrm{mL}) / 22.5$.

IR was arbitrarily defined as HOMA-IR value above the 75 th percentile of normal glucose tolerance, equal $2.45 \mathrm{mmol} / \mathrm{L} \times \mu \mathrm{U} / \mathrm{mL}$.

\section{Statistics}

Statistical analysis of the obtained results was performed in the SPSS system for Windows, Version 22 (SPSS Inc, Chicago, IL, USA). The data were presented as mean $(M)$ and standard deviation $( \pm S D)$ or $95 \%$ confidence interval (CI). To compare the main parameters of patient cohorts, a two-tailed Student ttest or Mann-Whitney U-test were used. To compare categorical variables between cohorts, the Chi2 
test $(\chi 2)$ and Fisher $F$ exact test were performed. The three consequent comparisons for variables between each other and baseline were analysed using post-hoc ANOVA method with the Duncan test. A two-tailed probability value of $<0.05$ was considered as significant.

\section{RESULTS}

The characteristics of the entire patient study population and both treatment arm cohorts are reported in Table 1. Among all groups of patients, moderate hypertension (2nd stage of hypertension) was found in 37 (49\%) patients, severe hypertension (stage 3 ) - in 38 (51\%), stage I AO found in $50(67 \%)$ patients, stage II - in $25(33 \%)$ patients. In the group of patients who were included in the study, a family history of hypertension was detected in 43 patients (78\%). The following metabolic disorders were found: 67 (89\%) patients with dyslipidaemia; 26 patients (35\%) with fasting hyperglycemia (FHG), 53 (71\%) patients with IR (HOMA-IR $\geq 2.77$ ) and 20 (27\%) patients with HUE. Occurrence of asymptomatic hypertension-mediated organs damage among examined patients was as follows: pulse $\mathrm{BP}(\mathrm{PBP})$ increase $(\mathrm{PBP} \geq 60 \mathrm{~mm} \mathrm{Hg}$ ) was diagnosed in 29 (39\%) patients, LVH - in 57 (76\%) patients, carotid IMT $>0.9 \mathrm{~mm}$ and/or atheromatous plaques - in 40 (53\%) patients, and reduced to 45-59 $\mathrm{ml} / \mathrm{min} / 1.73 \mathrm{~m}^{2}$ GFR (stage IIIa chronic kidney disease (CKD) was found in $13(170 \%)$ patients.

Figure 2 reports frequencies of BP target levels among all groups of patients. At 3 months and at 6 months of treatment, there were significant differences between numbers of patients in the groups having a target level of BP. Indeed, lower frequencies of BP target levels have appeared in patients treated with nonfixed triple combination in comparison with individuals taking triple fixed-does combination $(p<0.05)$. However, $53 \%$ and $85 \%$ in moderate-to-severe hypertensive patients treated with non-fixed and fixed-does combination were found as those who have achieved $\mathrm{BP}<140 / 90 \mathrm{~mm} \mathrm{Hg}$ after 6 months of treatment.

Additionally, 3-month and 6-month adherence to triple fixed-dose combination were higher $(82 \%$ and $87 \%$, respectively) in comparison with one to non-fixed combination ( $64 \%$ and $61 \%$, respectively) $(p<0.05)$ (Figure 3). While in the subgroup of patients treated with non-fixed combination of drugs adherence to therapy in 6 months tended to decrease compared to the rate of adherence in 3 months, in the group of patients who used fixed-dose combination of these drugs, adherence to treatment tended to increased with the continuation of treatment from 3 to 6 months from $82 \%$ to $87 \%$.

For both cohorts, step-by step elevation of doses among all compounds embedded onto fixed and nonfixed combinations was specified (Table 2). It has been established that low-dosed triple fixed combination $(4 \mathrm{mg} / 1.25 / 10 \mathrm{mg}$ and $8 \mathrm{mg} / 2.5 / 5 \mathrm{mg})$ were used frequently in the second cohort to the first cohort to achieve target blood pressure. Moreover, 39\% of patients, who were transferred to non-fixed combination, did not adhere to the given recommendations, and took only two medications (perindopril $8 \mathrm{mg}$ daily and amlodipine $5 \mathrm{mg}$ daily), or took medications irregularly or did not take any.

For individuals in the first and second cohorts with successful BP control, maximal doses of the agents (perindopril/indapamide/amlodipin: $8 \mathrm{mg} / 2.5 \mathrm{mg} / 10 \mathrm{mg}$ ) were required in $81 \%$ and $52 \%$ respectively $(\mathrm{p}<0.05)$ (Table 3$)$. Conversely, minimum and average doses of these agents were more commonly used by patients who were treated with fixed-dose combination, and reached target BP levels than by patients who were treated with non-fixed combination, and also reached target BP levels. It should be especially noted that $15 \%$ of patients with $\mathrm{AH}$ and $\mathrm{AO}$ treated with fixed-dose combination reached target BP levels after 6 months with minimum doses of these agents (perindopril/indapamide/amlodipin: $4 \mathrm{mg} / 1.25 / 10 \mathrm{mg}$ ). At the same time, such doses used in a non-fixed variation were not effective in patients to reach target levels of BP.

\section{Ambulatory BP monitoring}

6-month ABPM has shown that both triple nonfixed and triple fixed-dose combinations have driven a significant decrease in average daily systolic BP $(\mathrm{SBP}(24))$, average daytime systolic BP (SBP(D)), time-index 24-hour SBP (TISBP(24)) and time-index 24-hour DBP (TIDBP(24)) (Table 4). However, the triple fixed-dose combination has been proved to be much better in restoring the ABPM profile. Additionally, triple fixed-dose combinations' patients have exhibited significant decrease in average daily diastolic BP (DBP(24)), average daytime diastolic BP $(\mathrm{DBP}(\mathrm{D}))$, average night-time systolic BP (SBP(N)) and average night-time diastolic $\mathrm{BP}(\mathrm{DBP}(\mathrm{N}))$. Patients also showed significant increase in a degree of night-time SBP reduction (DNSBPR) and degree of night-time DBP reduction (DNDBPR) and significant decrease in average daily SBP variability $(\operatorname{SBPV}(24))$ and average daily DBP variability 


\begin{tabular}{|c|c|c|c|c|}
\hline Parameters & $\begin{array}{l}\text { Entire group } \\
(\mathrm{n}=75)\end{array}$ & $\begin{array}{l}\text { First cohort } \\
(\mathrm{n}=36)\end{array}$ & $\begin{array}{l}\text { Second cohort } \\
(\mathrm{n}=39)\end{array}$ & $\mathrm{p}$ value \\
\hline Age, years & $55.9 \pm 13.8$ & $53.6 \pm 13.3$ & $59.4 \pm 14.1$ & NS \\
\hline Male, n (\%) & $45(60 \%)$ & $22(61 \%)$ & $23(59 \%)$ & NS \\
\hline Female, n (\%) & $30(40 \%)$ & $14(39 \%)$ & $16(41 \%)$ & NS \\
\hline $\begin{array}{l}\text { Moderate arterial hypertension }\left(2^{n d} \text { stage }\right. \\
\text { of arterial hypertension), } \\
n(\%)\end{array}$ & $37(49 \%)$ & $18(50 \%)$ & $19(49 \%)$ & NS \\
\hline $\begin{array}{l}\text { Severe arterial hypertension } \\
\text { ( } 3^{r d} \text { stage of arterial hypertension), } \\
\mathrm{n}(\%)\end{array}$ & $38(51 \%)$ & $18(50 \%)$ & $20(51 \%)$ & NS \\
\hline Abdominal obesity stage $1, \mathrm{n}(\%)$ & $50(67 \%)$ & $23(64 \%)$ & $27(69 \%)$ & NS \\
\hline Abdominal obesity stage $2, \mathrm{n}(\%)$ & $25(33 \%)$ & $13(36 \%)$ & $12(31 \%)$ & NS \\
\hline Dyslipidaemia, n (\%) & $67(89 \%)$ & $32(89 \%)$ & $35(90 \%)$ & NS \\
\hline Metabolic syndrome, n (\%) & $72(96 \%)$ & $34(94 \%)$ & $38(97 \%)$ & NS \\
\hline LV hypertrophy, n (\%) & $57(76 \%)$ & $27(75 \%)$ & $30(77 \%)$ & NS \\
\hline Carotid IMT >0.9 mm, n (\%) & $40(53 \%)$ & $18(50 \%)$ & $22(57 \%)$ & NS \\
\hline LV mass index, $\mathrm{g} / \mathrm{m}^{2}$ (male) & $60.6 \pm 11.3$ & $57.2 \pm 11.7$ & $63.8 \pm 10.9$ & NS \\
\hline LV mass index, $\mathrm{g} / \mathrm{m}^{2}$ (female) & $54.5 \pm 11.3$ & $53.2 \pm 11.7$ & $56.8 \pm 10.9$ & NS \\
\hline Fasting glucose, $\mathrm{mmol} / \mathrm{L}$ & $5.1 \pm 1.3$ & $5.0 \pm 1.4$ & $5.2 \pm 1.5$ & NS \\
\hline Creatinine, $\mu \mathrm{mol} / \mathrm{L}$ & $90.4 \pm 21.1$ & $92.1 \pm 19.6$ & $89.3 \pm 22.4$ & NS \\
\hline $\mathrm{SUA}, \mu \mathrm{mol} / \mathrm{L}$ & $316.6 \pm 87.5$ & $307.9 \pm 82.3$ & $326.6 \pm 89.1$ & NS \\
\hline HOMA-IR, unit & $2.98 \pm 0.6$ & $2.86 \pm 0.55$ & $3.16 \pm 0.64$ & NS \\
\hline GFR, $\mathrm{ml} / \mathrm{min} / 1.73 \mathrm{~m}^{2}$ & $76.7 \pm 18.7$ & $79.2 \pm 19.3$ & $73.5 \pm 17.6$ & NS \\
\hline Total cholesterol, $\mathrm{mmol} / \mathrm{L}$ & $5.92 \pm 1.21$ & $5.57 \pm 1.17$ & $6.14 \pm 1.23$ & NS \\
\hline LDL cholesterol, mmol/L & $3.97 \pm 0.82$ & $3.66 \pm 0.79$ & $4.24 \pm 0.83$ & NS \\
\hline HDL cholesterol, $\mathrm{mmol} / \mathrm{L}$ (male) & $0.85 \pm 0.27$ & $0.96 \pm 0.26$ & $0.73 \pm 0.28$ & NS \\
\hline HDL cholesterol, mmol/L (female) & $1.12 \pm 0.27$ & $1.15 \pm 0.26$ & $1.03 \pm 0.28$ & NS \\
\hline Triglycerides, mmol/L & $2.33 \pm 0.38$ & $2.18 \pm 0.37$ & $2.54 \pm 0.41$ & NS \\
\hline
\end{tabular}

Abbreviations: SUA: serum uric acid, LV: left ventricular, IMT: intima-media thickness, GFR: glomerular filtration rate, HDL: cholesterol, high-density lipoprotein cholesterol, LDL: cholesterol, low-density lipoprotein cholesterol; NS: not significant

Notes: $p$ values were calculated between the first and the second cohorts

(DBPV(24)) (Table 4). Moreover, degrees of average daily systolic BP (SBP(24)), average daily diastolic BP (DBP(24)) and average night-time systolic BP $(\mathrm{SBP}(\mathrm{N}))$ reduction were sufficiently higher in triple fixed-dose combination patients compared to triple non-fixed combination individuals.

It was noted that there were no significant changes in SUA, serum uric and creatinine levels, estimating GFR, HOMA-IR, fasting glucose levels and BMI in both cohorts. Therefore, we did not find significant changes in LV mass index and carotid IMT for both cohorts.

\section{DISCUSSION}

It was established that neither one of the patients received a fixed-dose combination of anti-hypertensive agents before inclusion in the study. The largest proportion of patients $(80 \%)$ received two-component non-fixed combination of anti-hypertensive agents as a pre-study therapy. There was $47 \%$ of patients, 


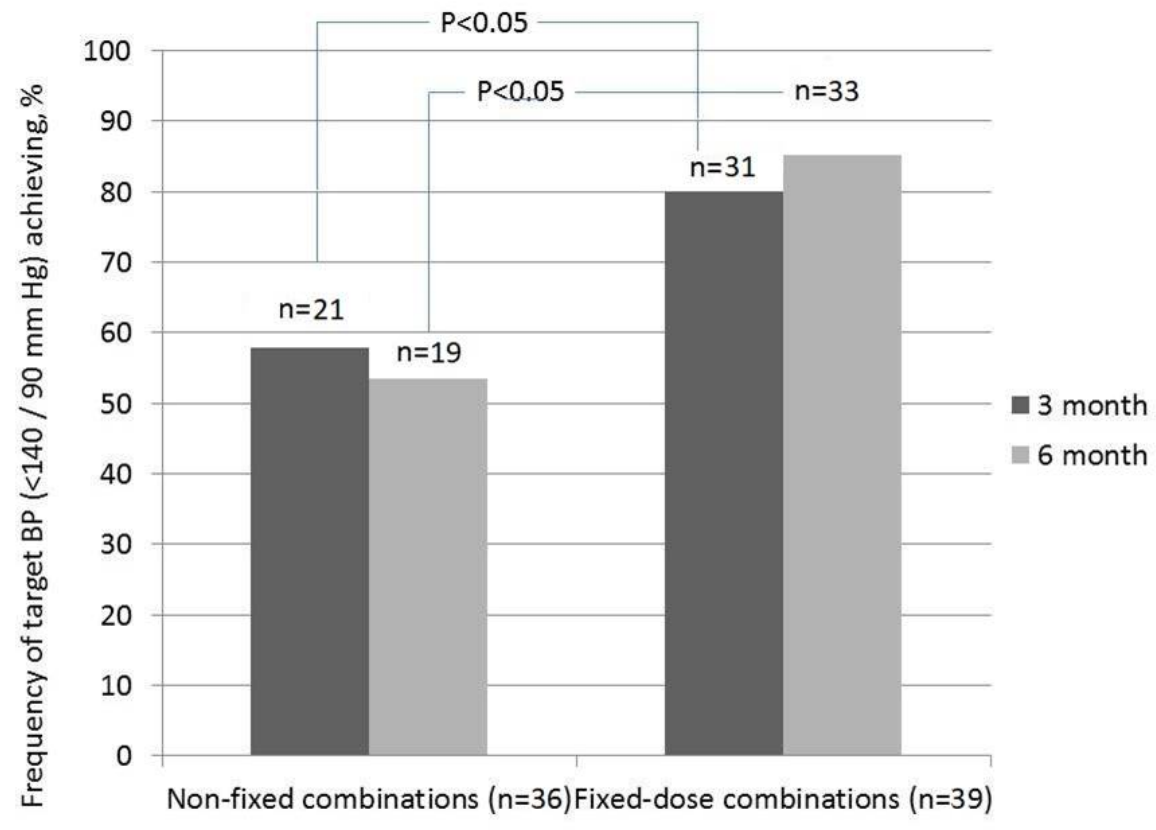

Figure 2: The frequencies of blood pressure target level achieving in both patient cohorts. There are significant differences between the numbers of the patients having target level of BP in 3 month and 6 month $(P<0.05$ for all cases). The BP target level has been achieved in 53\% and $85 \%$ in moderate-to-severe hypertensive patients treated with non-fixed and fixed-does combination respectively at 6 months of observation period.

Table 2: Proportionof patients in both cohorts who has been treated with different types offixed and non-fixed triple combinations at 6 month

\begin{tabular}{|c|c|c|c|c|c|}
\hline & \multicolumn{2}{|c|}{$\begin{array}{l}\text { Non-fixed triple } \\
\text { combination }(n=36)\end{array}$} & \multicolumn{2}{|c|}{$\begin{array}{l}\text { Fixed-dose triple } \\
\text { combination }(n=39)\end{array}$} & \multirow[t]{2}{*}{ p-value } \\
\hline & $\mathbf{n}$ & $\%$ & $\mathbf{n}$ & $\%$ & \\
\hline $\begin{array}{l}\text { Perindopril/indapamide/amlodipin: } \\
4 \mathrm{mg} / 1.25 \mathrm{mg} / 10 \mathrm{mg}\end{array}$ & 0 & 0 & 6 & 15 & $=0.001$ \\
\hline $\begin{array}{l}\text { Perindopril/indapamide/amlodipin: } \\
8 \mathrm{mg} / 2.5 \mathrm{mg} / 5 \mathrm{mg}\end{array}$ & 2 & 5 & 14 & 36 & $=0.044$ \\
\hline $\begin{array}{l}\text { Perindopril/indapamide/amlodipin: } \\
8 \mathrm{mg} / 2.5 \mathrm{mg} / 10 \mathrm{mg}\end{array}$ & 20 & 56 & 19 & 49 & NS \\
\hline $\begin{array}{l}8 \mathrm{mg} \text { Perindopril }+5 \mathrm{mg} \text { Amlodipin } \\
\text { (free combination) }\end{array}$ & 6 & 17 & 0 & 0 & $=0.012$ \\
\hline Took the medication irregularly & 5 & 14 & 0 & 0 & $=0.01$ \\
\hline Didn't take any medications & 3 & 8 & 0 & 0 & $>0.05$ \\
\hline
\end{tabular}

Abbreviation: NS: not significant

Notes: $p$ values were calculated between patients treated with fixed and non-fixed triple combinations 


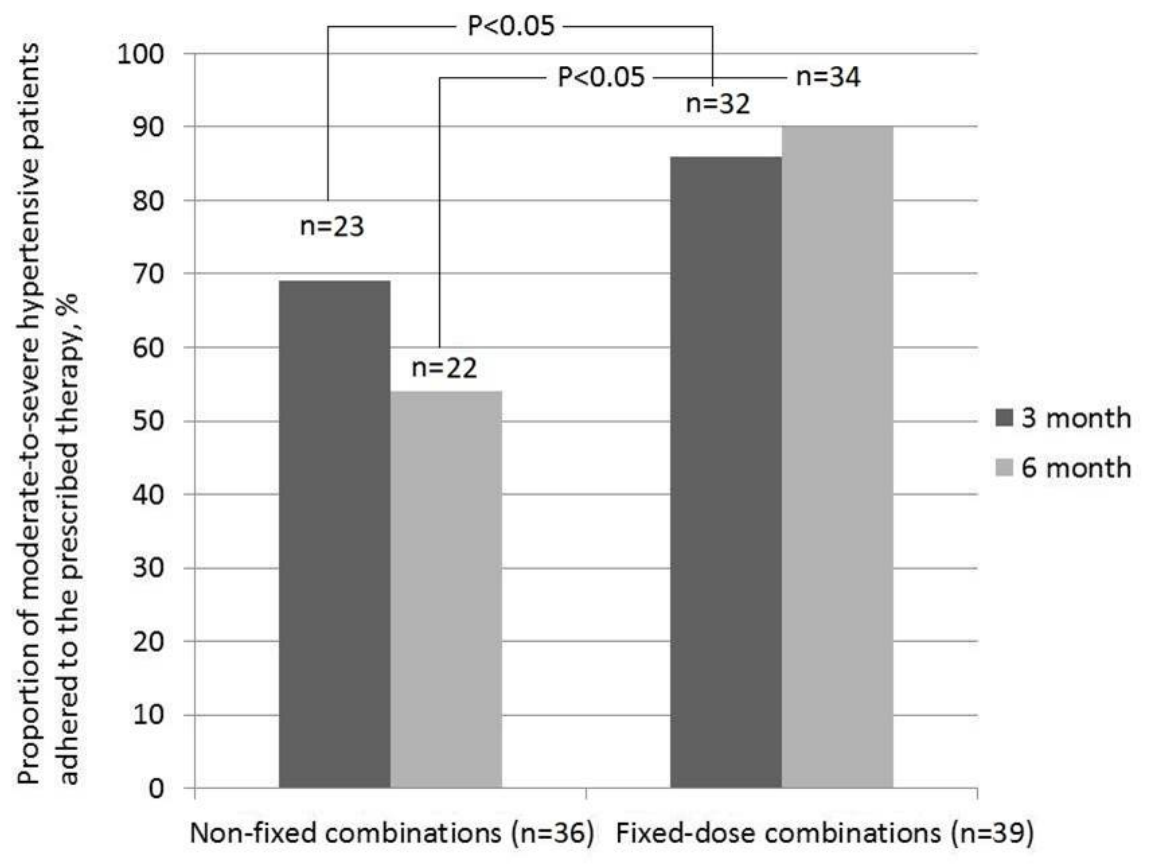

Figure 3: Proportion of patients who were adherent to the prescribed therapy at $\mathbf{3}$ month and $\mathbf{6}$ month. There were significantly higher 3-month and 6-month adherence to triple fixed-dose combination than non-fixed combination ( $p<0.05$ for all cases).

Table 3: Proportion of patients with full control BP at 6 month who has been treated with different types of fixed and non-fixed triple combinations

\begin{tabular}{|c|c|c|c|c|c|}
\hline & \multicolumn{2}{|c|}{$\begin{array}{l}\text { Non-fixed triple combination } \\
\qquad(n=21)\end{array}$} & \multicolumn{2}{|c|}{$\begin{array}{l}\text { Fixed-dose triple combination } \\
\qquad(\mathbf{n}=33)\end{array}$} & \multirow[t]{2}{*}{ p value } \\
\hline & $\mathrm{n}$ & $\%$ & $\mathrm{n}$ & $\%$ & \\
\hline $\begin{array}{l}\text { Perindopril/indapamide/amlodipin: } \\
4 \mathrm{mg} / 1.25 \mathrm{mg} / 10 \mathrm{mg}\end{array}$ & 0 & 0 & 5 & 15 & $=0.046$ \\
\hline $\begin{array}{l}\text { Perindopril/indapamide/amlodipin: } \\
8 \mathrm{mg} / 2.5 \mathrm{mg} / 5 \mathrm{mg}\end{array}$ & 4 & 19 & 11 & 33 & $=0.044$ \\
\hline $\begin{array}{l}\text { Perindopril/indapamide/amlodipin: } \\
8 \mathrm{mg} / 2.5 \mathrm{mg} / 10 \mathrm{mg}\end{array}$ & 17 & 81 & 17 & 52 & $=0.044$ \\
\hline
\end{tabular}

Notes: $p$ values were calculated between patients treated with fixed and non-fixed triple combinations

who received combination of an ACE inhibitor or an angiotensin II receptor blocker (ARB) and a thiazide or thiazide-like diuretic, $24 \%$ of patients received combination of an ACE inhibitor or an ARB and a long-acting dihydropyridine $\mathrm{CCB}$, and $9 \%$ of patients received combination of a beta-blocker and a thiazide-like diuretic. $20 \%$ of patients received a three-component combination of anti-hypertensive agents before inclusion in the study: ACE inhibitor or an ARB and a long-acting dihydropyridine CCB.
However, $60 \%$ of these patients received treatment irregularly and not in sufficiently optimal daily doses. Both subgroups of patients who were transferred to non-fixed and fixed-dose combinations did not differ significantly by the types of the described pre-study therapy.

Consequently, transferring patients with uncontrolled AH and AO to non-fixed and fixed-dose threecomponent anti-hypertensive therapy with perindopril, indapamide and amlodipine significantly in- 
Table 4: The results of ABPM in hypertensive patients with abdominal obesity treated with non-fixed and fixed-dose combinations of perindopril, indapamide and amlodipine

\begin{tabular}{|c|c|c|c|c|c|c|}
\hline \multirow[t]{2}{*}{ Variables } & \multicolumn{3}{|c|}{ Triple non-fixed combination $(n=36)$} & \multicolumn{3}{|c|}{ Triple fixed-dose combination $(n=39)$} \\
\hline & Baseline & 6 month & $\begin{array}{l}\text { Deviation } \\
\text { from } \\
\text { baseline }\end{array}$ & Baseline & 6 month & $\begin{array}{l}\text { Deviation } \\
\text { from baseline }\end{array}$ \\
\hline SBP(24), mm Hg & $151.31 \pm 10.67$ & $\begin{array}{l}136.35 \pm 11.09 \\
p<0.001\end{array}$ & $\begin{array}{l}- \\
14.96 \pm 1.29\end{array}$ & $155.69 \pm 10.87$ & $\begin{array}{l}128.12 \pm 12.26 \\
\mathrm{P}<0.05\end{array}$ & $\begin{array}{l}-22.93 \pm 1.54 \\
\mathrm{P} 1<0.05\end{array}$ \\
\hline $\begin{array}{l}\mathrm{DBP}(24), \quad \mathrm{mm} \\
\mathrm{Hg}\end{array}$ & $92.50 \pm 12.75$ & $84.69 \pm 10.95$ & $-6.8 \pm 2.95$ & $94.79 \pm 10.49$ & $\begin{array}{l}77.93 \pm 10.99 \\
p<0.001\end{array}$ & $\begin{array}{l}-15.86 \pm 1.12 \\
\mathrm{p} 1<0.05\end{array}$ \\
\hline $\mathrm{SBP}(\mathrm{D}), \mathrm{mm} \mathrm{Hg}$ & $160.27 \pm 12.18$ & $\begin{array}{l}140.62 \pm 10.88 \\
\mathrm{p}<0.001\end{array}$ & - $20.65 \pm 2.38$ & $162.59 \pm 10.66$ & $\begin{array}{l}134.76 \pm 11.15 \\
\mathrm{P}<0.001\end{array}$ & $\begin{array}{l}-28.83 \pm 3.56 \\
\mathrm{p} 1=0.05\end{array}$ \\
\hline $\mathrm{DBP}(\mathrm{D}), \mathrm{mm} \mathrm{Hg}$ & $94.23 \pm 10.46$ & $\begin{array}{l}86.23 \pm 11.85 \\
\text { NS }\end{array}$ & $7.15 \pm 1.91$ & $99.79 \pm 10.59$ & $\begin{array}{l}82.69 \pm 12.61 \\
p<0.001\end{array}$ & $\begin{array}{l}-16.86 \pm 3.32 \\
\mathrm{p} 1=0.05\end{array}$ \\
\hline $\mathrm{SBP}(\mathrm{N}), \mathrm{mm} \mathrm{Hg}$ & $135.10 \pm 11.52$ & $128.35 \pm 10.46$ & $\begin{array}{l}- \\
7.15 \pm 1.42\end{array}$ & $137.69 \pm 12.69$ & $\begin{array}{l}119.53 \pm 10.66 \\
\mathrm{p}<0.001\end{array}$ & $\begin{array}{l}-17.86 \pm 1.78 \\
\mathrm{p} 1<0.05\end{array}$ \\
\hline $\mathrm{DBP}(\mathrm{N}), \mathrm{mm} \mathrm{Hg}$ & $86.38 \pm 12.70$ & $73.73 \pm 10.75$ & $\begin{array}{l}- \\
8.65 \pm 2.40\end{array}$ & $88.62 \pm 11.71$ & $\begin{array}{l}69.13 \pm 10.89 \\
p<0.001\end{array}$ & $\begin{array}{l}-18.62 \pm 3.83 \\
\mathrm{p} 1=0.05\end{array}$ \\
\hline TISBP(24), \% & $83.89 \pm 16.88$ & $\begin{array}{l}33.38 \pm 13.53 \\
\mathrm{P}<0.001\end{array}$ & $\begin{array}{l}- \\
50.51 \pm 10.91\end{array}$ & $86.55 \pm 14.37$ & $\begin{array}{l}23.20 \pm 8.45 \\
p<0.001\end{array}$ & $\begin{array}{l}-63.36 \pm 10.29 \\
\mathrm{p} 1=0.05\end{array}$ \\
\hline $\operatorname{TIDBP}(24), \%$ & $62.65 \pm 12.91$ & $\begin{array}{l}31.27 \pm 9.59 \\
\mathrm{P}=0.01\end{array}$ & $\begin{array}{l}- \\
31.38 \pm 6.84\end{array}$ & $65.53 \pm 13.77$ & $\begin{array}{l}22.28 \pm 6.90 \\
p<0.001\end{array}$ & $\begin{array}{l}-42.26 \pm 10.12 \\
\mathrm{p} 1=0.05\end{array}$ \\
\hline DNSBPR,\% & $11.52 \pm 1.90$ & $\begin{array}{l}16.88 \pm 1.44 \\
p>0.05\end{array}$ & $5.37 \pm 1.06$ & $9.16 \pm 1.64$ & $\begin{array}{l}18.34 \pm 1.35 \\
p<0.001\end{array}$ & $\begin{array}{l}9.19 \pm 1.75 \\
\mathrm{pl}=0.05\end{array}$ \\
\hline DNDBPR,\% & $8.45 \pm 1.59$ & $\begin{array}{l}11.78 \pm 1.38 \\
p>0.05\end{array}$ & $3.33 \pm 0.74$ & $7.66 \pm 0.22$ & $\begin{array}{l}15.47 \pm 1.59 \\
p<0.001\end{array}$ & $\begin{array}{l}8.81 \pm 0.56 \\
\mathrm{p} 1=0.05\end{array}$ \\
\hline $\begin{array}{l}\text { SBPV(24), } \\
\text { mm Hg }\end{array}$ & $17.54 \pm 1.44$ & $\begin{array}{l}12.62 \pm 1.22 \\
\text { NS }\end{array}$ & $\begin{array}{l}- \\
4.92 \pm 0.74\end{array}$ & $20.10 \pm 1.35$ & $\begin{array}{l}9.34 \pm 0.92 \\
p<0.001\end{array}$ & $\begin{array}{l}-10.34 \pm 1.43 \\
\mathrm{p} 1=0.05\end{array}$ \\
\hline $\begin{array}{l}\operatorname{DBPV}(24), \\
\mathrm{mm} \mathrm{Hg}\end{array}$ & $15.62 \pm 1.36$ & $\begin{array}{l}10.42 \pm 1.21 \\
\mathrm{p}>0.05\end{array}$ & $\begin{array}{l}- \\
5.19 \pm 0.36\end{array}$ & $17.55 \pm 1.37$ & $\begin{array}{l}8.31 \pm 0.92 \\
\mathrm{p}<0.01\end{array}$ & $\begin{array}{l}-8.24 \pm 0.45 \\
\mathrm{p} 1=0.05\end{array}$ \\
\hline
\end{tabular}

Abbreviations: BP: blood pressure; SBP(24): average daily systolic BP; DBP(24): average daily diastolic BP; SBP(D): average daytime systolic BP;DBP(D): average daytime diastolic BP; SBP(N): average night-time systolic BP; DBP(N): average night-time diastolic BP; TISBP(24): timeindex 24-hour SBP, TIDBP(24): time-index 24-hour DBP; DNSBPR: degree of night-time SBP reduction; DNDBP:, degree of night-time DBP reduction; SBPV(24): average daily SBP variability; DBPV(24): average daily DBP variability; NS: not significant.

Notes: variables are given mean $(\mathrm{M})$ and standard deviation $(\mathrm{SD})$; $\mathrm{p}$ values were calculated between means of baseline and 6 -month; $\mathrm{p}^{1}$ values were calculated between means in patients treated with fixed and non-fixed triple combinations 
creased treatment efficacy. However, the use of a fixed-dose combination of these agents is significantly more effective than the use of the non-fixed combination.

One of the main reasons for achieving the higher and more stable effect of fixed-dose combination than non-fixed one was the better adherence to treatment in patients, who were treated with the fixed-dose combination of anti-hypertensive drugs ${ }^{16,19}$.

Of great clinical significance are the data obtained on complete normalization of the daily BP profile under the influence of the fixed-dose combination of perindopril, indapamide, and amlodipine, than that of under the influence of non-fixed combination ${ }^{5}$. It should be noted that the fixed-dose combination of these agents is useful in normalizing not only daily average and daytime average but also night-time average values of the daily BP profile.

An important result of this study was the absence of negative influence of the use of variants of non-fixed and fixed-dose combinations of perindopril, indapamide and amlodipine on metabolic parameters of patients with $\mathrm{AH}$ and $\mathrm{AO}^{5,15}$. The study showed that both non-fixed and fixed-dose combinations of these agents did not reduce efficacy of hypolipidemic therapy with average atorvastatin doses and contributed to significant decrease of dyslipidemia occurrence in patients with $\mathrm{AH}$ and $\mathrm{AO}$. Moreover, it was found that when these patients were treated with the fixed-dose combination, their BMI occurrence values were significantly lower.

Both variants of combined therapy allowed slowing down the progression of cardiovascular and kidney diseases, inhibit the increase of LVH levels, stiffness and vascular wall remodeling (PBP elevation and carotid IMT and/or growth, or appearance of new atheromatous plaques in CCA), and slow down GFR reduction.

One of the most considerable results of the study was that lower doses of perindopril, indapamide and amlodipine are required for achieving target BP levels in patients with uncontrolled $\mathrm{AH}$ and $\mathrm{AO}$ if these agents are used as a fixed-dose combination.

It was found that maximum doses of perindopril, indapamide, and amlodipine were required for achieving target BP levels in a significantly lower proportion of patients receiving fixed-dose combination as compared to patients receiving a non-fixed combination of specified products.

Overall, it should be noted that combining agents of three anti-hypertensive drug groups, such as an ACE inhibitor, a TLD and a long-acting dihydropyridine $\mathrm{CCB}$ in one tablet contributes to significant increase of anti-hypertensive efficacy compared to non-fixed combination of these agents in patients with uncontrolled $\mathrm{AH}$ and $\mathrm{AO}^{4,15,18}$. An influential result of this study was also confirming better adherence of patients with hypertension and AO to fixed-dose combination of perindopril, indapamide, and amlodipine than to non-fixed combination of these agents. According to modern beliefs, better adherence to therapy is one of the most critical factors determining the possibility of achieving optimal control of hypertension in the population ${ }^{5,16}$.

Thus, this study has shown feasibility and perspectivity of a fixed-dose three-component combination of perindopril, indapamide and amlodipine use in patients with uncontrolled $\mathrm{AH}$ and AO. This is confirmed by findings of a number of published studies conducted in different groups of patients with $\mathrm{AH}$ and, most importantly, in patients with insufficiently controlled hypertension.

\section{STUDY LIMITATIONS}

The main limitation of our study is the small number of patients. Because of this, it was not possible to perform subgroup analyses of the fixed-dose combination of perindopril, indapamide and amlodipine versus non-fixed combination within different subgroups (e.g., gender, age, hypertension, and obesity severity. Another potential limitation is that the post-baseline ABPM evaluation was done only at 6 months. Despite these limitations, the findings show the higher anti-hypertensive efficacy and more complete restoring of daily blood pressure profiles of the fixed-dose combination of perindopril, indapamide, and amlodipine in comparison with the non-fixed combination of these agents.

\section{CONCLUSIONS}

In conclusion, we found that the efficacy of the fixed-dose combination of perindopril, indapamide and amlodipine is significantly higher than non-fixed combination of these agents in patients with uncontrolled hypertension affected by AO. Using a fixeddose combination of perindopril, indapamide and amlodipine in patients with uncontrolled hypertension and AO allow to significantly increase patients' adherence to therapy by $26 \%$ compared to using the non-fixed combination. Patients with uncontrolled hypertension and AO receiving a fixed-dose combination of perindopril, indapamide, and amlodipine showed more complete normalization of the daily BP profile than patients receiving non-fixed combination. It was established that achievement of target BP 
levels in patients with uncontrolled $\mathrm{AH}$ and $\mathrm{AO}$ was possible at lower doses of perindopril, indapamide, and amlodipine when used as a fixed-dose combination rather than non-fixed (free) combination. Maximum doses of these agents were required for achieving target BP levels in a significantly lower proportion of patients, who received fixed-dose combination when compared to patients receiving a non-fixed combination of these products.

\section{ABBREVIATIONS}

ABPM: Ambulatory Blood Pressure Monitoring

ACE: angiotensin-converting enzyme

AH: arterial hypertension

Aml: amlodipine

AO: abdominal obesity

BMI: body mass index

BP: blood pressure

CAD: coronary artery disease

CCB: calcium channel blocker

CI: confidence interval

CV: cardiovascular

DBP: diastolic blood pressure

$\operatorname{DBP}(\mathbf{N})$ : average night-time diastolic blood pressure DBPV(24): average daily diastolic blood pressure variability

DNDBPR: degree of night-time diastolic blood pressure reduction

DNSBPR: degree of night-time systolic blood pressure reduction

GFR: glomerular filtration rate

HDL: high density lipoprotein cholesterol

HOMA-IR: homeostasis model assessment for insulin resistance

HUA: hyperuricemia

IMT: carotid intima-media segment thickness

Ind: indapamide

IR: insulin resistance

LDL: low density lipoprotein cholesterol

LVH: left ventricular hypertrophy

LVMMI: left ventricular myocardial mass index

MetS: metabolic syndrome

P: perindopril

SBP: systolic blood pressure

SBP(N): average night-time systolic blood pressure

SBPV(24): average daily systolic blood pressure vari-

ability

SUA: serum uric acid

TC: total cholesterol

TG: triglycerides
TIDBP(24): time-index 24-hour diastolic blood pressure TISBP(24): time-index 24-hour systolic blood pressure

TLD: thiazide-like diuretic

\section{COMPETING INTERESTS}

Not declared.

\section{FINANCIAL DISCLOSURE}

There has been no significant financial support for this work that could have influenced its outcome.

\section{AUTHORS' CONTRIBUTIONS}

S.M. Koval initiated the hypothesis and designed the study protocol. I.O. Snihurska enrolled the patients; collected and analyzed the data reviewed the source documents. T.G. Starchenko and M.Y. Penkova contributed to enroll the patients in the study and collected the data. O.V. Mysnychenko and K.O. Yushko performed of blood collection and interpreted of the obtained results. O.M. Lytvynova and O.V. Vysotska contributed to collect, analyze and interpret the data, and performed statistical analysis. A.E. Berezin performed statistical analysis, wrote the manuscript and approved final version of the paper. All authors read the manuscript before submitting and agree with final version of the paper.

\section{STATEMENT OF ORIGINALITY}

The authors do hereby declare that all materials used herein are original. This study is not under consideration for publication elsewhere. We confirm that the manuscript has been read and approved by all named authors and that there are no other persons who satisfied the criteria for authorship but are not listed. We further confirm that the order of authors listed in the manuscript has been approved by all of us. We understand that the Corresponding Author is the sole contact for the Editorial process (including Editorial Manager and direct communications with the office). $\mathrm{He}$ is responsible for communicating with the other authors about progress, submissions of revisions and final approval of proofs.

\section{ACKNOWLEDGMENTS}

We thank all patients for their participation in the investigation, and the doctors, nurses, and administrative staff in the Government Institution "L.T. Malaya Therapy National Institute of the National Academy of Medical Science of Ukraine" (Kharkiv, Ukraine). 


\section{REFERENCES}

1. Sinnott SJ, Smeeth L, Williamson E, Douglas IJ. Trends for prevalence and incidence of resistant hypertension: population based cohort study in the UK 1995-2015. BMJ. 2017;358:j3984. PMID: 28939590. Available from: 10.1136/ bmj.j3984.

2. Amiri $P$, Vahedi-Notash $G$, Naseri $P$, Khalili $D$, Nazari SSH, Mehrabi $Y$, et al. National trends of pre-hypertension and hypertension among Iranian adolescents across urban and rural areas (2007-2011). Biol Sex Differ. 2019;10(1):15. PMID: 30922399. Available from: 10.1186/s13293-019-0230-1.

3. Achelrod D, Wenzel U, Frey S. Systematic review and metaanalysis of the prevalence of resistant hypertension in treated hypertensive populations. Am J Hypertens. 2015;28(3):35561. PMID: 25156625 . Available from: 10.1093/ajh/hpu151.

4. James PA, Oparil S, Carter BL, Cushman WC, DennisonHimmelfarb C, Handler J, et al. 2014 evidence-based guideline for the management of high blood pressure in adults: report from the panel members appointed to the Eighth Joint National Committee (JNC 8). JAMA. 2014;311(5):507-20. PMID: 24352797. Available from: 10.1001/jama.2013.284427.

5. Williams B, Mancia G, Spiering W, Rosei EA, Azizi M, Burnier M, et al. $2018 \mathrm{ESC} / \mathrm{ESH}$ Guidelines for the management of arterial hypertension. Eur Heart J. 2018;39(33):3021-104. PMID: 30165516. Available from: 10.1093/eurheartj/ehy339.

6. Falaschetti E, Mindell J, Knott C, Poulter N. Hypertension management in England: a serial cross-sectional study from 1994 to 2011. Lancet. 2014;383(9932):1912-9. PMID: 24881995. Available from: 10.1016/S0140-6736(14)60688-7.

7. Egan BM, Zhao Y, Axon RN, Brzezinski WA, Ferdinand KC. Uncontrolled and apparent treatment resistant hypertension in the United States, 1988 to 2008. Circulation. 2011;124(9):1046-58. PMID: 21824920. Available from: 10. 1161/CIRCULATIONAHA.111.030189.

8. Armario $P$, Calhoun DA, Oliveras A, Blanch P, Vinyoles E, Banegas JR, et al. Prevalence and Clinical Characteristics of Refractory Hypertension. J Am Heart Assoc. 2017;6(12):e007365. PMID: 29217663. Available from: 10.1161/JAHA.117.007365.

9. Orlando A, Viazzi F, Giussani M, Nava E, Cazzaniga E, Bonino $B$, et al. Endothelin-1/nitric oxide balance and HOMA index in children with excess weight and hypertension: a pathophysiological model of hypertension. Hypertens Res. 2019;42(8):1192-9. PMID: 30923371. Available from: 10.1038/ s41440-019-0253-3.

10. Becker BD, Borghi C, Burnier $M$, van de Borne P. Uric acid and hypertension: a focused review and practical recommendations. J Hypertens. 2019;37(5):878-83. PMID: 30620339. Available from: 10.1097/HJH.0000000000001980.

11. Koval SM, Snihurska IO, Vysotska O, Strashnenko HM, Wójcik W, Dassibekov K. Prognosis of essential hypertension progression in patients with abdominal obesity.; 2019 . Available from: 10.1201/9780429057618-32.

12. Kario K, Thijs L, Staessen JA. Blood Pressure Measurement and Treatment Decisions. Circ Res. 2019;124(7):990-1008. PMID: 30920932. Available from: 10.1161/CIRCRESAHA.118. 313219.

13. Gupta AK, Arshad S, Poulter NR. Compliance, safety, and effectiveness of fixed-dose combinations of antihypertensive agents: a meta-analysis. Hypertension. 2010;55(2):399-407. PMID: 20026768. Available from: 10.1161/HYPERTENSIONAHA.109.139816.

14. Mancia G, Rea F, Corrao G, Grassi G. Two-Drug Combinations as First-Step Antihypertensive Treatment. Circ Res. 2019;124(7):1113-23. PMID: 30920930. Available from: 10. 1161/CIRCRESAHA.118.313294.

15. Ettehad D, Emdin CA, Kiran A, Anderson SG, Callender T, Emberson J, et al. Blood pressure lowering for prevention of cardiovascular disease and death: a systematic review and meta- analysis. Lancet. 2016;387(10022):957-67. PMID: 26724178. Available from: 10.1016/S0140-6736(15)01225-8.

16. Schroeder K, Fahey T, Ebrahim S. How can we improve adherence to blood pressure-lowering medication in ambulatory care? Systematic review of randomized controlled trials. Arch Intern Med. 2004;164(7):722-32. PMID: 15078641. Available from: 10.1001/archinte.164.7.722.

17. Vysotska OV, Koval SM, Bespalov YG, Pecherska Al, Lytvynova OM, Dyvak AM. Mathematical simulation of the structure of pulsed arterial pressure relations with vascular damage fac tors in patients with arterial hypertension.; 2019. Available from: 10.1201/9780429057618-32.

18. Walsh JM, McDonald KM, Shojania KG, Sundaram V, Nayak $\mathrm{S}$, Lewis $\mathrm{R}$, et al. Quality improvement strategies for hypertension management: a systematic review. Med Care. 2006;44(7):646-57. PMID: 16799359. Available from: 10.1097/ 01.mlr.0000220260.30768.32.

19. Glynn LG, Murphy AW, Smith SM, Schroeder K, Fahey T. Interventions used to improve control of blood pressure in patients with hypertension; 2010. Available from: 10.1002/14651858. CD005182.pub4.

20. Catapano AL, Graham I, Backer GD, Wiklund O, Chapman MJ, Drexel H, et al. 2016 ESC/EAS Guidelines for the Management of Dyslipidaemias: The Task Force for the Management of Dyslipidaemias of the European Society of Cardiology (ESC) and European Atherosclerosis Society (EAS) Developed with the special contribution of the European Assocciation for Cardiovascular Prevention \&amp; Rehabilitation (EACPR). Atherosclerosis. 2016;253:281-344. PMID: 27594540. Available from: 10.1016/j.atherosclerosis.2016.08.018.

21. Alberti KG, Eckel RH, Grundy SM, Zimmet PZ, Cleeman Jl, Donato $K A$, et al. Harmonizing the metabolic syndrome: a joint interim statement of the International Diabetes Federation Task Force on Epidemiology and Prevention; National Heart, Lung, and Blood Institute; American Heart Association; World Heart Federation; International Atherosclerosis Society; and International Association for the Study of Obesity. Circulation. 2009;120(16):1640-5. PMID: 19805654. Available from: 10.1161/CIRCULATIONAHA.109.192644.

22. on Detection ENCEPNEP, of High Blood Cholesterol in Adults (Adult Treatment Panel III) T. Third Report of the National Cholesterol Education Program (NCEP) Expert Panel on Detection, Evaluation, and Treatment of High Blood Cholesterol in Adults (Adult Treatment Panel III) final report. Circulation. 2002;106(25):3143-421. PMID: 12485966. Available from: 10.1161/circ.106.25.3143.

23. Lindson-Hawley N, Begh R, McDermott MS, McEwen A, Lycett $D$. The importance of practitioner smoking status: a survey of NHS Stop Smoking Service practitioners. Patient Educ Couns. 2013;93(1):139-45. PMID: 23711634. Available from: 10.1016/ j.pec.2013.04.021.

24. Organization WH. Waist circumference and waist-hip ratio report of a WHO expert consultation. Geneva: World Health Organization; 2008.

25. Gómez-Marcos MA, Recio-Rodríguez Jl, Patino-Alonso MC, Agudo-Conde C, Gómez-Sanchez L, Gómez-Sanchez M, et al. Protocol for measuring carotid intima-media thickness that best correlates with cardiovascular risk and target organ damage. Am J Hypertens. 2012;25(9):955-61. PMID: 22717546. Available from: 10.1038/ajh.2012.72.

26. Levey AS, Stevens LA, Schmid CH, Zhang YL, Castro AF, Feldman $\mathrm{HI}$, et al. A new equation to estimate glomerular filtration rate. Ann Intern Med. 2009;150(9):604-12. PMID: 19414839. Available from: 10.7326/0003-4819-150-9-200905050-00006.

27. Matthews DR, Hosker JP, Rudenski AS, Naylor BA, Treacher DF, Turner RC. Homeostasis model assessment: insulin resistance and beta-cell function from fasting plasma glucose and in sulin concentrations in man. Diabetologia. 1985;28(7):412-9. PMID: 3899825. Available from: 10.1007/BF00280883. 